\title{
Prevalence and Associated Factors of Zinc Deficiency Among Pregnant Women Attending Antenatal Care at Gambella Hospital, Gambella, Ethiopia, 2018
}

\author{
Ataguade Mekonnen ${ }^{1, *}$, Wondwossen Terefe ${ }^{2, ~ *}$, Abate Bekele Belachew ${ }^{2, *}$, \\ Amaha Kahsay Adhanu, ", Kebede Embaye Gezae ${ }^{2}$ \\ ${ }^{1}$ Department of Human Nutrition and Dietetics, School of Public Health, Gambella of Health Sciences, Gambella, Ethiopia \\ ${ }^{2}$ Department of Human Nutrition and Dietetics, School of Public Health, Mekelle University, Mekelle, Ethiopia
}

Email address:

atmk2004@gmail.com (A. Mekonnen),kidfwoynt4@gmail.com (W. Terefe), abateb144@gmail.com (A. B. Belachew), amahakahsay@gmail.com (A. K. Adhanu),aredom14@gmail.com (K. E. Gezae)

${ }^{*}$ Corresponding author

\section{To cite this article:}

Ataguadil Mekonnen, Wondwossen Terefe, Abate Bekele Belachew, Amaha Kahsay Adhanu, Kebede Embaye Gezae. Prevalence and Associated Factors of Zinc Deficiency Among Pregnant Women Attending Antenatal Care at Gambella Hospital, Gambella, Ethiopia, 2018. American Journal of Life Sciences. Vol. 7, No. 5, 2019, pp. 91-99. doi: 10.11648/j.ajls.20190705.12

Received: May 30, 2019; Accepted: October 21, 2019; Published: October 30, 2019

\begin{abstract}
It has been evidenced that zinc deficiency has an adverse effect on both mother and fetus, and subsequent birth outcomes and child survival. However, data on the prevalence and determinants of zinc deficiency among pregnant women are scanty in the country. Thus, this study was aimed to assess the prevalence of zinc deficiency and its associated factors among pregnant mothers attending antenatal care in the study setting in particular and the country in general. Hospital based crosssectional study was done in Gambella Hospital, Southwest Ethiopia from January to March, 2016. A randomly selected 246 pregnant women were included in this study. Blood samples were collected to analyze biochemical indicators of zinc deficiency. A multivariable logistic regression analysis was done to assess the effect of various explanatory variables on the serum zinc level. The mean serum zinc concentration was $58.75 \mu \mathrm{g} / \mathrm{dl}(95 \% \mathrm{CI}: 56.10-61.41)$. The overall prevalence of zinc deficiency among pregnant women was $55.3 \%$ (95\% CI: 50.0-61.3). Zinc deficiency was positively associated with short birth interval ( $\mathrm{AOR}=2.6 ; 95 \% \mathrm{CI}: 1.08-6.27$ ), the third trimester ( $\mathrm{AOR}=3.76 ; 95 \% \mathrm{CI}: 1.49-9.49)$, failure to consume diet of animal source ( $\mathrm{AOR}=2.4 ; 95 \% \mathrm{CI}: 1.01-5.74)$, inadequate dietary diversity ( $\mathrm{AOR}=3.59 ; 95 \% \mathrm{CI}: 1.45-8.96$ ), low serum albumin level $(\mathrm{AOR}=3.05 ; 95 \% \mathrm{CI}: 1.31-7.08)$, and anemia $(\mathrm{AOR}=3.09 ; 95 \% \mathrm{CI}: 1.19-7.95)$. More than half $(55.3 \%)$ of pregnant women had biochemical evidence of zinc deficiency. Moreover, the magnitude of zinc deficiency was pronounced among pregnant mothers with short birth interval, advanced gestational age, minimal intake of animal food sources, inadequate dietary diversity score, low serum albumin level, and low hemoglobin level (anemia). Therefore, effort should be made to encourage pregnant mothers to consume balanced diet including animal food sources particularly in their third trimester, to monitor their hemoglobin and serum albumin levels, and strengthening family planning implementations to prevent the occurrence of zinc deficiency.
\end{abstract}

Keywords: Cross Sectional Study, Gambella, Pregnant Women, Zinc Deficiency

\section{Introduction}

Zinc is one of the essential trace element for all forms of life and vital micronutrients with diverse physiologic and metabolic functions. [1] The total body zinc content of human subjects is 1.5-3.0 grams and it is the second most abundant trace element in the body next to iron (4 grams). [2]
This mineral is an essential cofactor for more than 300 enzymes participating in the metabolism of macromolecules as well as micronutrients. Thus, zinc is important in regulating basic cellular functions such as Deoxyribonucleic acid (DNA) replication, ribonucleic acid (RNA) transcription, cell division and activation. However, too extreme zinc level can lead to these abnormal body function. 


\section{$[3,4]$}

$\mathrm{ZD}$ in humans is resulted from reduced dietary intake, inadequate absorption, increased zinc loss, or increased zinc demands by the body system. However, the most common cause is reduced dietary intake. In the United States, the Recommended Dietary Allowance (RDA) is $8 \mathrm{mg} /$ day for women and $11 \mathrm{mg} /$ day for men. [5]

Zinc Deficiency (ZD) during pregnancy can negatively affect both the mother and fetus and thus complicated birth outcomes. Major problems associated with ZD are: increased maternal morbidity, pregnancy induced hypertension, fetal neural tube defects, premature rupture of membrane, low birth weight, poor neurobehavioral development, cognitive impairment, intrauterine growth retardation, impaired glucose tolerance, congenital malformations, stillbirths, preterm labor, postpartum hemorrhage, prolonged or nonprogressed labor and delivery, inefficient uterine contraction, abnormalities in gene replication, delayed immune system development which leads to increased neonatal morbidity and mortality rate. $[3,6,7] \mathrm{ZD}$ has also serious consequences for health including impairment of the immune system and as a result increasing the prevalence of childhood infections such as diarrhea and pneumonia, and impaired maternal health and poor pregnancy outcome. [7, 8]

Pregnant women in developing countries are susceptible to multiple micronutrient deficiencies including ZD. Pregnancy is associated with physiological changes and increased metabolic demands that results in increased plasma volume of blood, decreased concentrations of circulating nutrientbinding proteins and micronutrients, poor bio-absorption. All these conditions are obvious and most common to pregnant women. [3, 9] Increased nutritional demands during pregnancy predispose pregnant women to develop ZD. Because zinc requirements for fetal growth are high, Pregnant women are more susceptible to ZD, particularly in 2nd and 3rd trimesters. [6] Globally, It is estimated that $82 \%$ of pregnant women likely have inadequate zinc consumption. [8] However, the deficiency of zinc is more prevalent in women from poor socioeconomic groups. [10]

In 2004 International Zinc Nutrition Consultative Group (IZiNCG) estimated that $21.1 \%$ of Ethiopian population was at risk of inadequate dietary zinc intake. Where diets are plant based rich in phytate, a compound which is known to inhibit zinc absorption and bioavailability. [3] In light of this fact, in most areas of Ethiopia consumption of animal sources is mostly limited to occasional public holidays, which indicated inadequate intake. [11] Hence, this might be the reason for the expected high ZD prevalence in the country. The hot climatic condition of the region may also increase zinc loss from the body. [3]

$\mathrm{ZD}$ is increasingly being recognized as a major public health problem and the risk factors for low serum zinc level concentration believed to exist. However, there is no regionally representative figure on zinc status of the population. Nothing is being done so far in Ethiopia to address ZD except for the short-term zinc supplementation targeting children with diarrhea. However, the extents of ZD among pregnant women are not fully understood in the study setting in particular and the country in general and this challenges us in the expansion of prevention strategies to control ZD in the population. Therefore, this study was aimed to assess the magnitude and associated factors of ZD among pregnant women attending Antenatal care (ANC) at Gambella Hospital, Gambella, Ethiopia.

\section{Materials and Methods}

Study design and setting

A hospital based cross-sectional study was conducted at Gambella Hospital, Gambella, Southwest Ethiopia from January to March, 2016. It is located at $768 \mathrm{~km}$ far southwest from the capital of Ethiopia, Addis Ababa. The city has an elevation ranging from 400 to 600 meters above sea level and largely hot climatic zone. The hospital provides surgical, medical, pediatric, gynecologic, and obstetric including ANC service among many other services to the community and displaced people from South Sudan. According to the 2014 annual plan and performance report of Gambella Hospital, 15 to 20 pregnant women visited the hospital's ANC clinic daily on average and thus 700 pregnant women had ANC follow up during two months attendance in the hospital.

Sampling size determination and Sampling technique

The sample size was determined by using single population proportion formula using EPI info version7 assuming the prevalence of zinc deficiency among pregnant women was $57.4 \%$ [12], 5\% margin of error, and 5\% level of significance. There were finite number of mothers attending the ANC clinic at the hospital and thus, the final sample size was estimated to be 268 by adding $10 \%$ for non-response rate. The study subjects were selected by systematic random sampling one for every three mothers visited the ANC clinic in the hospital during the study period and to avoid redundancy client card numbers were coded.

Data collection procedures and Variable measurements

Data were collected using pretested structured questionnaire that was adopted from different similar literatures. It was used to collect data on serum zinc concentration and its associated risk factors based on the conceptual framework of the study. It was prepared first in English then translated into Amharic and Agnuac languages. Finally, the questionnaires were administered in both Amharic and Agnuac languages. Trained Diploma midwives and laboratory technicians were involved in the data collection and supervisions were also supervised by two nursing professionals.

DDS Assessment: The DDS assessment tool was adopted from Food and Nutrition Technical Assistance (FANTA) indicator guide for measuring household and individual DDS. [13] The women dietary diversity level was assessed using 24 hour recall method. Respondents were asked whether they had taken any foods or liquids from predefined 9 food groups in the previous day of the survey. Based on a set list of nine food items (Starchy staples, dark-green leafy vegetables, vitamin A rich fruits and vegetables, other fruits and 
vegetables, organ meat, meats and fish, eggs, legumes, nuts and seeds, milk and milk products), DDS less than four out of nine score was categorized as inadequate otherwise it was categorized as adequate DDS. [13]

\section{Anthropometric measurements}

To assess nutritional status of pregnant women, measurements of Mid Upper Arm Circumference (MUAC) was taken from all selected pregnant women using a nonstretchable MUAC tape. It is done after study subjects removed their jackets. A triplicate measurement of MUAC was taken at the same day from each study subject using standardized techniques. All measurements had been taken twice and the average had been computed. When the two measurements differ by one unit, the measurement had been repeated. Checking accuracy of the scale and frequent calibrating of the scale was done. Calibration was done before and after weighing every pregnant woman setting it to zero. Those with a MUAC value less than $22 \mathrm{~cm}$ were considered as malnourished and above 22 are well nourished.

Blood sample collection, Processing and Transportation

A venous blood sample of 5 milliliters $(5 \mathrm{ml})$ was collected from the median-antecubital vein under aseptic conditions using a sterile trace elements-free evacuated blood collection tube. The same day, the serum samples were kept frozen at $-20^{\circ} \mathrm{C}$ at Gambella regional laboratory until it is transported to the laboratory of the Ethiopian Public Health Institute (EPHI). Serum was kept in an ice box during transportation.

Serum zinc determination and zinc deficiency

Both non-fasting and fasting blood samples were collected following standard procedures for serum zinc analysis. Serum zinc concentration was determined at EPHI using Shimadzu Flame Atomic Absorption Spectroscopy (AA 6800 model, Japan). The pregnant woman is zinc deficient if the serum zinc level is less than $56 \mu \mathrm{g} / \mathrm{dl}$ during the first trimester or less than $50 \mu \mathrm{g} / \mathrm{dl}$ during the second or third trimester. [3]

\section{Hemoglobin and albumin levels determination}

Hemoglobin was determined at Gambella Hospital. Hemoglobin concentration was estimated by Hemo Cue haemoglobinometer. This device is non-invasive requiring only a small volume of blood $(10 \mu \mathrm{l})$ and confers high sensitivity, specificity, and positive predictive value for evaluation of blood hemoglobin. [14] Albumin was also determined at Gambella hospital. Albumin level was measured by Roche cobas intgera ${ }^{\circledR} 400$ plus chemistry analyzer machine. Albumin deficiency is defined as a serum albumin level less than $3.2 \mathrm{~g} / \mathrm{dl}$ during pregnancy [15]. In addition, Anemia among pregnant women is defined as a hemoglobin level of (at sea level) less than $11.0 \mathrm{~g} / \mathrm{dl}$ during the first or third trimester or less than $10.5 \mathrm{~g} / \mathrm{dl}$ during the second trimester. [13]

\section{CRP determination and HIV status screening}

CRP was determined qualitatively using CRP-Latex following the procedure provided with the kit. In addition, rapid test for HIV (1/2) antibody from whole blood was also performed by serial testing algorithm. The algorithm includes KHB as a screening test, Stat pack as a confirmatory test and
Uni-gold as a tie breaker test.

\section{Data processing and statistical analysis}

The collected data were coded and entered using EPI-Info version-7 software. The data were exported to SPSS version 20 statistical software for further cleaning and analysis. The descriptive statistics show the distribution of respondents by the key variables. Descriptive statistics such as frequencies with percentages and mean with standard deviation were used to present categorical and continuous variables, respectively. Bar graphs are also used to summarize categorical variables. Multivariable binary logistic regression analysis was used to assess the effect of different explanatory variables on the zinc status and to control potential confounders. Finally, multivariable analysis was run for significant variables in the bivariate analysis of logistic regression and thus, variables with $\mathrm{P}$-value $\leq 0.05(5 \%)$ were considered as statistically significant predictors of $\mathrm{ZD}$ prevalence in the final logistic regression model. Moreover, the Adjusted Odds Ratio (AOR) and 95\% Confidence Interval (CI) were interpreted and discussed for the statistically significant predictors of $\mathrm{ZD}$ prevalence in the study.

\section{Ethics approval and consent to participate}

Ethics approval was issued by Institutional Review Board (IRB) of Mekelle University, College of Health Sciences (Protocol Reference: ERC 06104/2016) and a written informed consent was obtained from the study subjects prior to data collection after explaining the purpose and procedures of the study. Health care workers read out and explained the information to illiterate participants and obtained written consent on their behalf. While, for subjects who were less than 18 years of age, assent was sought from their spouse as legal guardian for those who were not married and thus, parental consent was also considered in this situation. Moreover, the privacy, anonymity, voluntary participation and confidentiality were ensured.

\section{Results}

Background characteristics of the study participants

Of the total 268 pregnant women (15-49 years of age) selected, $246(91.4 \%)$ were interviewed with an acceptable non-response rate less $8.6 \%$. One hundred sixty-five $(67.1 \%)$ of the study participants were urban dwellers. Slightly more than half (51.6\%) of the study participants were youth (25-34 years old). Approximately, $46.0 \%$ of study subjects were Protestants. Regarding the educational status, 56 (22.8\%) of pregnant women were illiterate. Nearly half (47.5\%) of the pregnant women were housewives. Almost all of the study participants (95.5\%) had married marital status. Almost twothird $(67.1 \%)$ of the study subjects were urban dwellers and $165(66.3 \%)$ of pregnant women had family size of 4-5. Source of drinking water for more than half (54.9\%) of study participants was tap water. Unlikely, more than one fifth $(20.7 \%)$ of pregnant women had well water source of drinking (Table 1). 
Table 1. Background characteristics of the pregnant women attending ANC at Gambella Hospital, Gambella, Southwest Ethiopia, 2016 (n=246).

\begin{tabular}{|c|c|c|}
\hline Variables & Frequency & Percentage \\
\hline \multicolumn{3}{|l|}{ Age (in years) } \\
\hline $15-24$ & 73 & 29.7 \\
\hline $25-34$ & 127 & 51.6 \\
\hline $35-49$ & 46 & 18.7 \\
\hline \multicolumn{3}{|l|}{ Religion } \\
\hline Orthodox & 92 & 37.4 \\
\hline Protestant & 112 & 45.5 \\
\hline Muslim & 26 & 10.6 \\
\hline Catholic & 16 & 6.5 \\
\hline \multicolumn{3}{|l|}{ Ethnicity } \\
\hline Agnuac & 53 & 21.5 \\
\hline Amhara & 52 & 21.1 \\
\hline Oromo & 46 & 18.7 \\
\hline Nuer & 39 & 15.9 \\
\hline Others* & 56 & 22.8 \\
\hline \multicolumn{3}{|l|}{ Marital status } \\
\hline Married (living with a partner) & 235 & 95.5 \\
\hline Others** & 11 & 4.5 \\
\hline \multicolumn{3}{|l|}{ Residence } \\
\hline Urban & 165 & 67.1 \\
\hline Rural & 81 & 32.9 \\
\hline \multicolumn{3}{|l|}{ Educational status } \\
\hline Illiterate & 56 & 22.8 \\
\hline Can write and read & 23 & 9.3 \\
\hline Primary education (1-8) & 83 & 33.7 \\
\hline Secondary education.(9-12) & 41 & 16.7 \\
\hline Higher education*** & 43 & 17.5 \\
\hline \multicolumn{3}{|l|}{ Occupation } \\
\hline House wife & 116 & 47.2 \\
\hline Governmental employed & 36 & 14.6 \\
\hline Farmer & 27 & 11 \\
\hline Merchant & 25 & 10.2 \\
\hline Self-employed & 18 & 7.3 \\
\hline Others**** & 24 & 9.8 \\
\hline \multicolumn{3}{|l|}{ Family size } \\
\hline$\leq 3$ & 67 & 27.2 \\
\hline $4-5$ & 163 & 66.3 \\
\hline$\geq 6$ & 16 & 16.5 \\
\hline \multicolumn{3}{|l|}{ Family monthly income } \\
\hline$\leq 1000$ Ethiopian birr & 77 & 31.3 \\
\hline 1001-2000 Ethiopian birr & 90 & 36.6 \\
\hline >2001 Ethiopian birr & 79 & 32.1 \\
\hline \multicolumn{3}{|l|}{ Latrine availability } \\
\hline Yes & 199 & 80.9 \\
\hline No & 47 & 19.1 \\
\hline \multicolumn{3}{|l|}{ Source of water } \\
\hline Tape water & 135 & 54.9 \\
\hline Spring water & 60 & 24.4 \\
\hline Well water & 51 & 20.7 \\
\hline
\end{tabular}

*Opo/kemo/Tigray/Kembat/Wolayita/Gurage/Kafa;**Single/Divorced/Wido wed;***College/University;****Day laborer/student

Reproductive health and health care related characteristics of the study participants

Seventy four $(30.1 \%)$ of the study participants had first ever pregnancy in the study. More than one third $(37.8 \%)$ and almost two-fifth $(40.2 \%)$ of pregnant women had inadequate birth interval and were in the third trimester of pregnancy respectively. In addition, $117(47.6 \%)$ of the study participants were received nutritional education during their ANC follow-up. Among those pregnant women who attended ANC, $65(26.4 \%)$ of them were received iron supplementation as medication during their pregnancy period. The reproductive health and health care characteristics of the study subjects were presented in (Table 2).

Table 2. Reproductive health and health care related characteristics of pregnant women attending ANC at Gambella Hospital, Gambella, Southwest Ethiopia, $2016(n=246)$

\begin{tabular}{lll}
\hline Variables & Frequency & Percentage \\
\hline Parity & 74 & 30.1 \\
0 & 101 & 41.0 \\
$1-2$ & 57 & 23.2 \\
$3-4$ & 14 & 5.7 \\
$\geq 5$ & & \\
Birth interval & 74 & 30.1 \\
0 (no birth) & 93 & 37.8 \\
6-23 months & 79 & 32.1 \\
$\geq 24$ months & & \\
Period of pregnancy in trimesters & 56 & 22.8 \\
First trimesters (0-12 week) & 91 & 37.0 \\
Second trimesters (13-28 week) & 99 & 40.2 \\
Third trimesters (29-40 week) & & \\
Received nutrition education during & & \\
pregnancy & 117 & 47.6 \\
Yes & 129 & 52.4 \\
No & & \\
Received iron supplementation during & & \\
pregnancy & 65 & 26.4 \\
Yes & 181 & 73.6 \\
No & & \\
Suffered any illness during pregnancy & 107 & 43.5 \\
Sick & 139 & 56.5 \\
Not sick & & \\
Types of illness during pregnancy period* & 28 & 11.4 \\
Acute fever illness /malaria, typhoid/ & 29 & 11.7 \\
Pregnancy related disorder & 50.3 \\
Others** & & \\
Type of treatment/medications given* & 19 \\
Haven't received & 67 & 27.4 \\
Anti-malaria & & \\
Other treatment*** & & \\
\hline & & \\
& & \\
\hline
\end{tabular}

*multiple response were possible; ** Helimentasis/pneumonia; ***Pain killer/traditional remedies.

\section{Nutrition related characteristics of the study participants}

The staple diet for the majority $(44.5 \%)$ of the study participants was Teff. More than three-fourth $(81.7 \%)$ of the study subjects were consuming coffee. Regarding the DDS of the pregnant women, the more than half $(52.4 \%)$ of study participants had inadequate DDS. Only ninetythree $(37.8 \%)$ of pregnant women were consumed diet of animal origin. The highly consumed food groups by the study participants, $244(99.2 \%)$ were starchy and cereal based foods composed of Teff, Wheat, Sorghum, and Millet and $53.1 \%$ of the study subjects consumed diet of legumes, nuts and seeds in the previous 24 hours. However, only few (12.2\%) of the study participants were provided with organ meat and eggs. Moreover, the nutritionally related characteristics of the study participants were summarized in (Table 3). 
Table 3. Nutrition related characteristics of pregnant women attending ANC at Gambella Hospital, Gambella, Southwest Ethiopia, 2016 (n=246).

\begin{tabular}{lll}
\hline Variables & Frequency & Percentage \\
\hline Types of staple diets* & & \\
Millet & 37 & 15.0 \\
Teff & 109 & 44.5 \\
Maize & 96 & 39.0 \\
Others** & 4 & 1.5 \\
Consumed animal source foods & & \\
Yes & 93 & 37.8 \\
No & 153 & 62.2 \\
Types of consumed animal source food & & \\
Fish & 92 & 37.4 \\
Meat & 36 & 14.6 \\
Others*** & 22 & 9.0 \\
Frequency of animal source food & & \\
Very rare/ holidays & 106 & 43.1 \\
once per weeks & 37 & 15.0 \\
3-6 per weeks & 87 & 35.4 \\
2 per months & 16 & 6.5 \\
Dietary diversity score & & \\
Adequate & 117 & 47.6 \\
Inadequate & 129 & 52.4 \\
Frequency of meal intake per day & & \\
$\geq 3$ times & 182 & 74.0 \\
$<3$ times & 64 & 26.0 \\
Frequency of coffee intake per day & & \\
No take coffee & 45 & 18.3 \\
×3 cup of coffee & 165 & 67.1 \\
$>3$ cup of coffee & 36 & 14.6 \\
\hline
\end{tabular}

**Wheat/Sorghum/rice; ***Milk and its product/eggs /organ meat.

\section{Clinical characteristics of the study participants}

The lower proportion, $14(5.7 \%)$ of the study participants were positive for HIV. Nearly one-third, 79 (32.1\%) of the pregnant women had anemia on the basis of their hemoglobin levels $(<11 \mathrm{~g} / \mathrm{dl})$. A substantial proportion, $105(42.7 \%)$ of the pregnant women had low serum albumin level $(<3.2 \mathrm{~g} / \mathrm{dl})$. More than one-third of the study participants $(38.2 \%)$ were undernourished (Table 4).

Table 4. Clinical characteristics of pregnant women attending ANC at Gambella Hospital, Southwest Ethiopia, 2016 ( $n=246)$.

\begin{tabular}{lll}
\hline Variables & Frequency & Percentage \\
\hline HIV Status & & \\
Positive & 14 & 5.7 \\
Negative & 224 & 91.1 \\
Refuse & 8 & 3.2 \\
\hline
\end{tabular}

\begin{tabular}{lll}
\hline Variables & Frequency & Percentage \\
\hline Nutritional status (MUAC) & & \\
Undernourished $(<22 \mathrm{~cm})$ & 94 & 38.2 \\
Normal $(\geq 22 \mathrm{~cm})$ & 152 & 61.8 \\
Serum albumin level $(\mathrm{g} / \mathrm{dl})$ & & \\
$<3.2$ & 105 & 42.7 \\
$\geq 3.2$ & 141 & 47.3 \\
Hemoglobin level $(\mathrm{g} / \mathrm{dl})$ & & \\
$\leq 11$ & 79 & 32.1 \\
$>11$ & 167 & 67.9 \\
\hline
\end{tabular}

Prevalence of Zinc deficiency among the study participants

The majority of the blood samples 190 (77.2\%) were collected in the morning. Nearly half of the participants, 121 $(49.2 \%)$ were non-fasting. The overall prevalence of zinc deficiency was $55.3 \%$ (95\% CI: 50.0-61.3). The mean serum zinc concentration of pregnant women in this study was 58.75 (95\% CI: $56.10-61.41)$ with SD of $21.11 \mu \mathrm{g} / \mathrm{dl}$. The prevalence of ZD during the first, second and third trimesters were $64.3 \%, 38.5 \%$, and $65.7 \%$, respectively.

Factors associated with zinc deficiency in multivariable logistic regression analysis

Birth interval, trimester (gestational age), animal source food, dietary diversity score, serum albumin and hemoglobin level were significantly associated with zinc deficiency (Table 5). The odds of zinc deficiency was 2.6 times higher among pregnant women with short birth interval $(<24$ months) as compared to those with optimal ( $\geq 24$ months) birth interval ( $\mathrm{AOR}=2.60 ; 95 \% \mathrm{CI}$ : 1.08-6.27) keeping effect of other risk factors constant. The odds of ZD was 3.7 times higher among third trimester women as compared to those in first trimester $(\mathrm{AOR}=3.76 ; 95 \% \mathrm{CI}$ : 1.49-9.49). The odds of ZD were more than 3 times higher among pregnant women with anemia than pregnant women who had no anemia $(\mathrm{AOR}=3.09 ; 95 \% \mathrm{CI}: 1.19-7.95)$. The odds of $\mathrm{ZD}$ were 3 times higher among pregnant women with albumin deficiency than pregnant women who had adequate serum albumin levels (AOR=3.05; 95\% CI: 1.31-7.07). Generally, the statistically significant predictors of $\mathrm{ZD}$ prevalence among pregnant women in the current study were summarized in (Table 5).

Table 5. Risk factors associated with zinc deficiency among pregnant women attending ANC at Gambella Hospital, Southwest Ethiopia, 2016 ( $n=246)$.

\begin{tabular}{|c|c|c|c|c|}
\hline \multirow{3}{*}{ Predicators } & \multicolumn{2}{|l|}{ Zinc status } & \multirow{3}{*}{ COR $(95 \% C I)$} & \multirow{3}{*}{$\operatorname{AOR}(95 \% C I)$} \\
\hline & ZD & Normal & & \\
\hline & Freq. (\%) & Freq. (\%) & & \\
\hline \multicolumn{5}{|l|}{ Birth interval } \\
\hline$<24$ months & $70(75.3)$ & $23(24.7)$ & $3.28(1.72-6.26)^{*}$ & $2.6(1.08,6.27)^{* *}$ \\
\hline$\geq 24$ months & $38(48.1)$ & $41(51.9)$ & 1 & 1 \\
\hline \multicolumn{5}{|l|}{ Trimester } \\
\hline First & $36(64.3)$ & $20(35.7)$ & 1 & 1 \\
\hline Second & $35(38.5)$ & $56(61.5)$ & $1.06(0.56,2.11)$ & $0.84(0.31-2.22)$ \\
\hline Third & $65(65.7)$ & $34(34.3)$ & $3.06(1.69,5.53)^{* *}$ & $3.76(1.49,9.49)^{* *}$ \\
\hline \multicolumn{5}{|c|}{ Consumed animal source of food } \\
\hline Yes & $44(47.3)$ & $49(52.7)$ & 1 & 1 \\
\hline No & $92(60.1)$ & $61(39.9)$ & $1.68(0.99,2.83)$ & $2.40(1.01,5.74)^{* *}$ \\
\hline Dietary diver: & & & & \\
\hline
\end{tabular}




\begin{tabular}{|c|c|c|c|c|}
\hline \multirow{3}{*}{ Predicators } & \multicolumn{2}{|l|}{ Zinc status } & \multirow{3}{*}{ COR $(95 \% \mathrm{CI})$} & \multirow{3}{*}{ AOR (95\%CI) } \\
\hline & ZD & Normal & & \\
\hline & Freq. (\%) & Freq. (\%) & & \\
\hline Adequate & $62(53.0)$ & $55(47.0)$ & 1 & 1 \\
\hline Inadequate & $74(57.4)$ & $55(42.6)$ & $1.91(0.72,1.96)$ & $3.59(1.45,8.96)^{* *}$ \\
\hline \multicolumn{5}{|c|}{ Receive nutrition education } \\
\hline Yes & $47(40.2)$ & $70(59.8)$ & 1 & 1 \\
\hline No & $89(69.0)$ & $40(37.0)$ & $3.31(1.96,5.6)^{* *}$ & $2.41(0.91,6.43)$ \\
\hline \multicolumn{5}{|c|}{ Albumin deficiency } \\
\hline No & $63(44.7)$ & $78(55.3)$ & 1 & 1 \\
\hline Yes & $73(69.5)$ & $32(30.5)$ & $2.82(1.66,4.81)^{* *}$ & $3.05(1.31,7.07)^{* *}$ \\
\hline \multicolumn{5}{|l|}{ Anemia } \\
\hline No & $77(46.1)$ & $90(53.9)$ & 1 & 1 \\
\hline Yes & $59(74.7)$ & $20(25.3)$ & $3.45(1.91,6.23)^{*}$ & $3.09(1.19,7.95)^{* *}$ \\
\hline
\end{tabular}

* Significant at p-value: $\leq 0.05 ; * *$ P-value $\leq 0.01 ; 1=$ Reference

\section{Discussion}

In the current study, more than half $(55.3 \%)$ of pregnant women had biochemical evidence of zinc deficiency based on their low serum zinc concentration. According to the IZiNCG, ZD is a public health concern when the prevalence is greater than $20 \%$. [3] Thus, the study provides the evidence for the public health concern of ZD in the study setting. [1]

The finding of the current study is in line with similar studies conducted in Sidama (53\%) [16], Gondar (57.4\%) [12], India (55.5\%) [17], and China (51.5\%). [18] The possible explanation could be similarity in soil zinc levels and feeding style though it needs further investigations. Conversely, the findings were much lower than that of the prevalence of ZD reported from the Southern Ethiopia (72\%, $74 \%$ and 76\%) [19-21], Northwest Ethiopia (66.7\%) [21], Nigeria (97.2\%) [22], Kenya (66.9\%) [23], Cameroon (82\%) [24], Turkey (72.3\%) [25] and India (64.6\% and 72\%). [26, 27] This discrepancy may be due to socio-economic difference and seasonal variation in the study period. Moreover, most of the other studies included different population by culture and geographical area which may contribute for the difference in prevalence unlike the current study. [3, 8, 28] Furthermore, in the study setting, consumption of animal food source especially fish is very common even considered as staple food which are good source of zinc. [3, 4] Moreover, the prevalence may be overestimated as only pregnant women from rural areas in the third trimester were included in the study from Sidama and India, unlike the present study which targeted all pregnant women of urban and rural dwellers.

The high prevalence of $\mathrm{ZD}$ in this study as compared to the similar studies conducted in Addis Ababa, Ethiopia (11.3\%) [29], Pakistan (27.8\%) [30], Eastern and Central Sudan (38\% and 45\%) [31, 32], Malawi (46\%) [33], Iran (29\% and 49\%) [34, 35], Vietnam (29\%) [36], Bangladesh (14.7\%) [37], and Uruguay (7-14\%) [38] might be explained by the high food insecurity in the study setting is leading to lack of access to adequate, safe, and nutritious food which in turn leads to low zinc concentration. Moreover, crops grown locally will have low zinc content and households who depend entirely on locally produced crops will be more likely to develop ZD because of the low zinc contents of the Ethiopian soil. [39] Furthermore, the studies may have underestimated the prevalence as they had only included pregnant women in early pregnancy in study from Bangladesh and Vietnam, unlike the present study which targeted all pregnant women as study subjects.

The current study has also revealed that birth interval, gestational age (trimester), DDS, animal food sources, hemoglobin level, and serum albumin level were identified as statistically significant risk factors of $\mathrm{ZD}$ among pregnant women.

Birth interval was one of the significant risk factor influencing positively the biochemical zinc status of pregnant women. Too short birth interval was significantly associated with ZD among pregnant women. This might be supported by the understanding that repeated pregnancies deplete maternal nutritional store and this could also positively affect the serum zinc status of the pregnant women as a result of the inter-gestational link. This finding is in line with previous studies conducted in Northwest Ethiopia (Gondar), Southern Ethiopia (Sidama), India, Malawi and Nigeria.[12, 16, 26, 33, 38] Contrary to this study finding, a study from Turkey did not find any statistically significant association between zinc status and birth interval. [25] The variation might be explained by difference in socio-economic and demographic factors and nutritional status prior to and during pregnancy.

Result of the current study also revealed that the trimester (gestational age) of the pregnant women is statistically associated with ZD prevalence. Thus, gestational age was positively associated with ZD in the study. Similar findings were reported from Sidama, Southern Ethiopia. [20, 21] Like wisely, similar studies conducted in Bangladesh, Pakistan and Turkey $[25,30,37]$ were also supported the finding. This could be reflecting more about the influence of pregnancy is interacted with physiological changes and increased metabolic demands. Different hypothesis include, changes in protein level secondary to physiological adoption, hormonal effect, increased metabolic demands that result an expansion of plasma volume and red blood cells, and maternal fetal transfer of zinc. [39] It is also decreased concentrations of circulating nutrient-binding proteins and micronutrients, poor bio-absorption and its increased nutritional demands during 
pregnancy predispose pregnant women to develop zinc deficiency. Because, zinc requirements for fetal growth are high and thus, pregnant women are more susceptible to zinc deficiency, particularly in second and third trimesters. [6, 7] A common finding during pregnancy is hypoalbuminemia and high levels of estrogens, which may be associated with low concentration of zinc.

Food of animal source was also significantly associated with ZD prevalence among pregnant women. Pregnant mothers who did not consume animal source foods had low serum zinc concentration as compared to those who consumed animal source foods. The finding of the current study is consistent with similar studies conducted in Malawi, Vietnam, Sudan, Northwest Ethiopia (Gondar) and Southern Ethiopia (Sidama). $[12,16,32,33,36]$ The present study revealed a high dependency on consumption of plants diets: cereals $(99.4 \%)$ and legumes (53.3\%) among pregnant women. Basically, these diets contain high level of phytates, the most potent inhibitors of zinc absorption and bio-availability. [3]

In the current study, a serum zinc level was found to be depleted among pregnant women with inadequate DDS. On the other hand, pregnant women with inadequate DDS were more likely to develop $\mathrm{ZD}$ as compared to those with adequate DDS. This finding is in line with the study conducted in Southern Ethiopia (Sidama) and Northwest Ethiopia (Gondar). [12, 16] Additionally, previous studies conducted in India, Malawi, Kenya, Sudan, and Nepal [19, $23,26,40,41]$ were also supported the finding. The decreased prevalence of zinc deficiency is justified by the concept that increasing the variety of foods and food groups in the diet helps to ensure adequate intake of essential nutrients including zinc and promotes good health. [42] Another possible justification may be as the number of consumed foods increase the chance of including animal sources of food in the diet is high, which are good sources of zinc. This reason is strengthened by the fact that greater dietary diversification and modification of diets can enhance availability and utilization of foods with a high content of absorbable zinc and it has been associated with better nutritional outcomes and improved micronutrient intake. [3]

Similarly, anemia is identified a statistically significant predictor of ZD prevalence in the current study. Thus, pregnant mothers with anemia diagnosis were more likely to have $\mathrm{ZD}$ as compared to those mothers with no anemia diagnosis. The finding of the present study is in-consistent with other similar studies conducted in Sudan. [31, 32, 40] Conversely, the result of this study is in line with other similar studies conducted in Nigeria, Nepal, Northwest Ethiopia (Gondar), Southern Ethiopia (Sidama). [12, 16, 19, 38, 41] Moreover, Iron and zinc deficiencies in pregnant women may occur simultaneously as a result of an increased demand for zinc and iron by pregnant women, and also more likely, poor intake and poor bio-absorption of iron and zinc. On the other hand, as zinc is known to participate in multiple metabolic reactions, it might have causal role in anemia. Zinc is implicated in hemoglobin synthesis through the activity of several zinc dependent enzyme catalysis, including aminolevulinic acid dehydrase that mediates a step in the synthesis of heme. More recently, the zinc-finger transcription factor has also been confirmed as essential factor for normal erythropoiesis or the common dietary sources of iron and zinc. $[19,40]$ Other potential mechanisms may involve the stimulation of hematopoiesis by zincinduced plasma insulin-like growth factor-1 levels and the role of zinc in stabilizing cell membranes. [43]

Finally, the findings of this study indicated that low serum albumin level was positively associated with the serum zinc level of pregnant women. Albumin deficient pregnant women had 3 fold greater risk of being zinc deficient compared to those with adequate serum albumin level. Therefore, the finding of this study was supported by similar studies conducted in Malawi, Northwest Ethiopia (Gondar). [12, 19] The finding strengthens the knowledge that serum zinc concentration declines in relation to serum albumin level during pregnancy, due to expansion in plasma volume. In addition, Serum zinc concentration also falls with the hypoalbuminemia, which positively affects absorption and transport of zinc. [3].

\section{Conclusion}

Overall, the prevalence of ZD among pregnant women in the study was $55.3 \%$. The prevalence was high among pregnant women: with short birth interval, in the third trimester, low intake of animal food sources, low dietary diversity score, low serum albumin level (hypoalbuminemia) and low hemoglobin level (anemia). Therefore, effort should be made to encourage pregnant mothers to consume balanced diet including animal food sources particularly in their third trimester, to monitor their hemoglobin and serum albumin levels, and strengthening family planning implementations to prevent the occurrence of zinc deficiency. However, further prospective follow up studies were recommended to confirm the cause-effect (temporal) relationship between anemia and ZD and population based prospective studies should be also conducted to assess the magnitude, severity and risk factors of ZD in the country.

\section{Abbreviations}

ANC: Antenatal Care AOR: Adjusted Odds Ratio CI: Confidence Interval COR: Crude Odds Ratio CRP: C reactive protein DDS: Dietary Diversity Score EPHI: Ethiopian Public Health Institute HIV: Human Immunodeficiency Virus IZiNCG: International Zinc Nutrition Consultative Group MUAC: Mid Upper Arm Circumference SD: Standard Deviation WHO: World Health Organization ZD: Zinc Deficiency.

\section{Acknowledgements}

We authors are thankful to Mekelle University, College of Health Sciences, for giving us this opportunity to conduct the research. 


\section{Disclosure}

We authors declared that we have no competing interests.

\section{Availability of Data and Materials}

The data that support our conclusion of the study are obtained from the corresponding author up on reasonable request. Because, the data set is not shared publicly.

\section{References}

[1] Hambidge M. Zinc and Health: Current status and future directions. Journal of Nutrition. 2000; 130: 1344S-1349S.

[2] NairK M, Choudhury DR. Zinc nutrition in health and diseases. Journal of SAT Agricultural. 2013.

[3] Brown KH, Rivera JA, Bhutta Z, Gibson RS, King JC, Lönnerdal B, Ruel MT, Sandtröm B, Wasantwisut E, Hotz C, de Romaña DL. International Zinc Nutrition Consultative Group (IZiNCG) technical document\# 1. Assessment of the risk of zinc deficiency in populations and options for its control. Food and nutrition bulletin. 2004; 25 (1 Suppl 2).

[4] Joint FAO and WHO. Vitamin and mineral requirements in human nutrition. 2005.

[5] Bales CW, Ritchie CS, editors. Handbook of clinical nutrition and aging. New York, NY, USA: Humana Press. 2009.

[6] Karimi A, Bagheri S, Nematy M, Saeidi M. Zinc Deficiency in Pregnancy and Fetal-Neonatal Outcomes and Impact of the Supplements on Pregnancy Outcomes. Iranian Journal of Neonatology (IJN). 2012; 3 (2): 77-83.

[7] Shah D, Sachdev HP. Effect of gestational zinc deficiency on pregnancy outcomes: Summary of observation studies and zinc supplementation trials. British Journal of Nutrition. 2001; 85 (2): 101-108.

[8] CaulfieldLE, Black RE. Zinc deficiency: Comparative quantification of health risks: global and regional burden of disease attributable to selected major risk factors. Geneva. 2004: $257-279$.

[9] Tamura T, Goldenberg RL, Johnston KE, Dubard M. Maternal plasma zinc concentrations and pregnancy outcome. The American journal of clinical nutrition. 2000; 71 (1): 109-113.

[10] Ugwuja EI, Akubugwo EI, Ibiam UA, Obidoa O. Maternal socio-demographic parameters: impact on trace element status and pregnancy outcomes in Nigerian women. Journal of health, population, and nutrition. 2011; 29 (2): 156.

[11] Getahun Z, Urga K, Ganebo T, Nigatu A. Review of the status of malnutrition and trends in Ethiopia. The Ethiopian Journal of Health Development (EJHD). 2017; 15 (2).

[12] Kumera G, Awoke T, Melese T, Eshetie S, Mekuria G, Feleke M, Ewunetu T, Gedle D. Prevalence of zinc deficiency and its association with dietary, serum albumin and intestinal parasitic infection among pregnant women attending antenatal care at the University of Gondar Hospital, Gondar, Northwest Ethiopia. BMC Nutrition. 2015; 1 (1): 31.

[13] Woteki CE, Earl R, editors. Iron deficiency anemia: recommended guidelines for the prevention, detection, and management among US children and women of childbearing age. National Academies Press. 1994.

[14] Be WK, Kerkkamp HE, Booij LH. Hemocue--a new haemoglobinometer in the clinic. European journal of anaesthesiology. 1991; 8 (1): 55-58.

[15] Lambein F, Haque R, Khan JK, Kebede N, Kuo YH. From soil to brain: zinc deficiency increases the neurotoxicity of Lathyrus sativus and may affect the susceptibility for the motorneurone disease neurolathyrism. Toxicon. 1994; 32 (4): 461-466.

[16] Gebremedhin S, Enquselassie F, Umeta, M. Enquselassie, and M. Umeta, Prevalence of prenatal zinc deficiency and its association with socio-demographic, dietary and health care related factors in Rural Sidama, Southern Ethiopia: A crosssectional study. BMC public health. 2011; 11 (1): 898.

[17] Pathak P, Kapil U, Kapoor S, Dwivedi S, Singh R. Magnitude of zinc deficiency among nulliparous nonpregnant women in a rural community of Haryana State, India. Food and nutrition bulletin. 2003; 24 (4): 368-371.

[18] Ma AG, Chen XC, Xu RX, Zheng MC, Wang Y, Li JS. Comparison of serum levels of iron, zinc and copper in anemic and non-anemic pregnant women in China. Asia Pacific journal of clinical nutrition. 2004; 13 (4).

[19] Gibson RS, Abebe Y, Stabler S, Robert H, Allen R, Westcott J, Stoecker B, Krebs N, Hambidge K. Zinc, Gravid, infection, and iron, but vitamin B-12 or foliate status, predict hemoglobin during pregnancy in southern Ethiopia. Journal of nutrition. Journal of nutrition. 2008; 138 (3): 538-586.

[20] Abebe Y, Bogale A, Hambidge KM, Stoecker BJ, Arbide I, Teshome A, Krebs NF, Westcott JE, Bailey KB, Gibson RS. Inadequate intakes of dietary zinc among pregnant women from subsistence households in Sidama, Southern Ethiopia. Public health nutrition. 2008; 11 (4): 379-386.

[21] Kassu A, Yabutani T, Mulu A, Tesema B, Ota F. Serum zinc, copper, selenium, calcium, and magnesium levels in pregnant and non-pregnant women in Gondar, Northwest Ethiopia. Biological trace element research. 2008; 122 (2): 97.

[22] Oguizu AD. Assessment of Iron, Selenium and Zinc Status of Pregnant Women in Obio-Akpor LGA Rivers State. Pakistan Journal of Nutrition. 2015; 14 (1): 1-5.

[23] Mitheko AN. Dietary, socio-economic and demographic factors influencing serum zinc levels of pregnant women at Naivasha level 4 hospital Nakuru County, Kenya. 2013.

[24] Engle-Stone R, Ndjebayi AO, Nankap M, Killilea DW, Brown KH. Stunting Prevalence, Plasma Zinc Concentrations, and Dietary Zinc Intakes in a Nationally Representative Sample Suggest a High Risk of Zinc Deficiency among Women and Young Children in Cameroon-3. The Journal of nutrition. 2013; 144 (3): 382-391.

[25] Açkurt F, Wetherict H, Löker M. Biochemical assessment of nutritional status in pre-and post-natal Turkish women and outcome of pregnancy. European Journal of Clinical Nutrition. 1995; 49 (8): 613-622.

[26] Pathak P, Kapil U, Dwivedi SN, Singh R. Serum zinc levels amongst pregnant women in a rural block of Haryana state, India. Asia Pacific journal of clinical nutrition. 2008; 17 (2): 276-279. 
[27] Rathi SS, Srinivas M, Grover JK, Mitra D, Vats V, Sharma JD. Zinc levels in women and newborns. Indian journal of pediatrics. 1999; 66 (5): 681-684.

[28] Walker CF, Ezzati M, Black R. Global and regional child mortality and burden of disease attributable to zinc deficiency. European Journal of Clinical Nutrition. 2009; 63 (5): 591-597.

[29] Haidar J, Umeta M, Kogi-Makau W. Effect of iron supplementation on serum zinc status of lactating women in Addis Ababa, Ethiopia. East African medical journal. 2005; 82 (7): $349-352$.

[30] Lutfullah G. Prevalence of zinc deficiency among rural women during childbearing age in Peshawar, Pakistan. Pak. J. Pharm. Sci. 2014; 27 (1): 173-177.

[31] Bushra M, Elhassan M, Naji I, Ali A, Osman E, Khalid H, Bakheit A, Adam I. Anaemia, zinc and copper deficiencies among pregnant women in central Sudan. Biological trace element research. 2010; 137 (3): 255-261.

[32] Shommo S, Zumrawi F, Saeed A. Micronutrients Dietary Intakes of Pregnant Sudanese Women. International Journal of Science and Research. 2013; 4 (4): 2319-7064.

[33] Gibson RS, Huddle JM. Suboptimal zinc status in pregnant Malawian women: its association with low intakes of poorly available zinc, frequent reproductive cycling, and malaria. The American journal of clinical nutrition. 1998; 67 (4): 702-709.

[34] Hanachi P, Golkho S, Norrozi M. The association of serum Zinc levels with socio demographic factors, red and white blood cells count in pregnant women. Journal of Applied Sciences. 2008; 8: 4679-4683.

[35] Roshanravan N, Alizadeh M, Hedayati M, Asghari-Jafarabadi M, Alamdari NM, Anari F, Tarighat-Esfanjani A. Effect of zinc supplementation on insulin resistance, energy and macronutrients intakes in pregnant women with impaired glucose tolerance. Iranian journal of public health. 2015; 44 (2): 211
[36] Nguyen VQ, Gotot A, Nguyen TVT, Vo KT, Ta TNT, Nguyen TNT, et al. Prevalence and correlates of zinc deficiency in pregnant Vietnamese women in Ho Chi Minh City. Asia Pacific journal of clinical nutrition. 2013; 22 (4): 614-619.

[37] Shamin AA, Merrill RD, Ali AH, Rashid M, Schulze K. Plasma zinc, vitamin B 12 and $\alpha$-tocopherol are positively and plasma $\gamma$-tocopherol is negatively associated with $\mathrm{Hb}$ concentration in early pregnancy in north-west Bangladesh. Public health nutrition. 2013; 16 (8): 1354-1361.

[38] Severi C, Hambidge M, Krebs N, Alonso R, Atalah E. Zinc in plasma and breast milk in adolescents and adults in pregnancy and pospartum: a cohort study in Uruguay. Nutrición Hospitalaria. 2013; 28 (1).

[39] King JC. Determinants of maternal zinc status during pregnancy. The American journal of clinical nutrition. 2000; 71 (5): 1334s-1343s.

[40] Mohamed AA, Ali AA, Ali NI, Abusalama EH, Elbashir MI, Adam I. Zinc, parity, infection, and severe anemia among pregnant women in Kassla, eastern Sudan. Biological trace element research. 2011; 140 (3): 284-290.

[41] Chandyo RK, Strand TA, Mathisen M, Ulak M, Adhikari RK, Bolann BJ, Sommerfelt H. Zinc deficiency is common among healthy women of reproductive age in Bhaktapur, Nepal. The Journal of nutrition. 2009; 139 (3): 594-597.

[42] Aldrian PS, Keen CL, Lönnerdal B, Dewey KG. Effects of coffee consumption on iron, zinc and copper status in nonpregnant and pregnant Sprague-Dawley rats. International journal of food sciences and nutrition. 1997; 48 (3): 177-189.

[43] Dash S, Brewer GJ, Oelshlegel FJ. Effect of zinc on haemoglobin binding by red blood cell membranes. Nature. 1974; 250 (5463): 251-252. 